\title{
Knowledge of Minor Discomforts during Pregnancy among Pregnant Women Attending Maternal and Pediatric Hospital in Soran City
}

\author{
Haroon M. Khalil, Kareem J. Hamad* \\ Department of Nursing, Soran Technical Institute, Erbil Polytechnic University, Kurdistan Region, Iraq
}

\author{
${ }^{*}$ Corresponding author: \\ Kareem J. Hamad, Department \\ of Nursing, Soran Technical \\ Institute, Erbil Polytechnic \\ University, Kurdistan Region, \\ Iraq. \\ E-mail: Kareem.hamad@epu. \\ edu.iq
}

Received: 29 January 2019

Accepted: 07 February 2019

Published: 30 October 2019

DOI

10.25156/ptj.v9n2y2019.pp20-24

\section{A B S T R A C T}

\begin{abstract}
A lot of pregnant women experience some common discomforts during their pregnancy which may occur due to hormonal, anatomical, and metabolic changes. Although common discomforts may make the pregnant woman feel ill, pregnancy is a normal physiologic process. The common discomforts include backache, leg cramps, constipation, fatigue, nausea and vomiting, sleep disturbance, heartburn, and increased urinary frequency. To assess the pregnant knowledge of minor discomforts happening during pregnancy, it is planned to conduct the present study. A descriptive study design was carried out from December 2017 to June 2018, using non-probability convenience sampling technique for the selection of 150 mothers attended maternal and pediatric hospital in Soran City during antenatal visits. Data were collected through the use of a specially designed questionnaire for the purpose of the study. The findings of the study show that $34 \%$ of samples were in the age group of $20-25$ years, $42 \%$ illiterate and mostly $(90 \%)$ housewife. Most of women $(70 \%)$ were in the $3^{\text {rd }}$ trimester of their pregnancy and $66 \%$ of them had not history of the previous abortion. More than half of the participants $(56 \%)$ had poor knowledge of minor discomforts during pregnancy. Our results show statistically significant association between knowledge levels with pregnant education level, and high significant association with age, husbands' education level, and occupation. In addition, significant associations were found between pregnant mothers' knowledge and their reproductive variables of gravida, abortion, and type of pregnancy. The major conclusion drawn on the basis of the findings of the present study was that there was inadequate knowledge of discomforts during pregnancy among participants. The study results revealed that women knowledge level was significantly associated with age, educational level, occupation, gravida, abortion, and type of pregnancy.
\end{abstract}

Keywords: Knowledge; Minor discomforts; Pregnancy; Pregnant women

\section{INTRODUCTION}

Pregnancy is creative and productive period in the life of a woman. It is one of the vital events, which needs special care from conception to postnatal period (Karnati and Kumari, 2015).

Pregnancy defined as the state of carrying a developing embryo or fetus within the female uterus.

During pregnancy, many physiologic and psychological changes occur that can positively or negatively affect the woman, her fetus, and her family (Gamel et al., 2017). A woman experiences remarkable change as a new human life is conceived and grows, occupying space within her uterus. Her anatomy and physiology adapt to sustain, nurture, and then finally birth the baby (Pierce, 2010).

There are some common problems or discomforts that a woman might experience during pregnancy but are not threatening their life, they are called minor discomforts (Hanif, 2006). Minor discomforts are slight ailments of pregnancy that leads to lack of comfort rather than disabling the pregnant woman. Although they are not serious, their presence detracts from the mothers feeling of comfort and well-being, especially if they occur daily and make her wonder if she will ever feel like herself again (El-Khayat, 2007).

As the pregnancy progresses the increasing size of the fetus produces physical stress on mothers' body and these pressure can also cause further uncomfortable symptoms. The majority of discomforts experienced during pregnancy can be associated to either hormonal changes or the physical changes related to growing fetus (Fraser and Copper, 2004).

In addition, Latha and Indira (2016), in another study, revealed that minor disorder may occur due to hormonal changes, accommodation changes, metabolic changes, and 
postural changes. Evidence from the study in New Delhi by Bala (2017) manifested that during pregnancy period, a woman undergoes many changes to accommodate the growing fetus and experience a variety of physiological and psychological symptoms such as nausea, vomiting, backache, and heartburn.

The good news is that lot of discomforts can be alleviated using some simple remedies and proper explanation, and fortunately, most of these discomforts will go away as pregnancy progresses (Dhanawade, 2017).

Concerning management of minor discomforts according to the study by Aziz and Maqsood (2016), non-pharmacological therapies should be considered as the first-line treatment before going to pharmacological therapy. However, medications may be used to ensure the well-being of the mother and prevent secondary adverse effects to the fetus or sometimes mothers.

Sangeetha et al. (2015) in a descriptive study assessed the level of knowledge of minor ailments among antenatal mothers and revealed that a lot of pregnant women do not know how to deal with the minor discomforts during pregnancy, their study indicated that important aspect during pregnancy is counseling on the discomforts of pregnancy to help the pregnant women distinguish between a normal discomfort and a real problem in the pregnancy. To find out what pregnant mothers know about minor discomforts happening during pregnancy and to discuss and educate pregnant women about discomforts type, causes, and proper practice for home management at a timely manner during interview period, it is planned to conduct the present study.

\section{METHODS}

The proposed design for this study was descriptive, which used to assess the level of knowledge of minor discomforts during pregnancy. The study was carried out, in Maternal and Pediatric Hospital in Soran City, between the periods of December 2017 and June 2018 on a sample of 150 pregnant women selected by nonprobability convenience sampling technique. Pregnant women who were attended hospital during the period of data collection and agreed to participate were included in the study. Verbal consent was taken from participants. Those who were sick had difficulty in communication and pregnant who refused participation were excluded from the study. Data were collected using a specially designed questionnaire by the researchers. Questionnaire consists of three parts: The first one was about pregnant women sociodemographic characteristics, the second part was for reproductive variables, and the last part was about knowledge regarding minor discomforts. Categorical responses (Yes, No) were applied for the question items and giving 1 point for each correct answer and 0 for incorrect.

The overall knowledge score for each participant was calculated by summing scores of 14 questions with possible range from 0 to 14 which divided into two categories: Poor knowledge (score $\leq 7$ ) and good knowledge (score $\geq 8$ ). For data analysis, Statistical Package for the Social Sciences (SPSS, version 18) was used to compute frequencies and percentage of different variables and Chi-square $\left(\mathrm{X}^{2}\right)$ analysis was used to identify any kind of association between different variables in the study. $P \leq 0.05$ was considered as statistically significant.

\section{RESULTS}

\section{Sociodemographic Characteristics of Participants}

In the present study from Table 1, it can be noticed that of 150 pregnant women interviewed, $34 \%$ were within the age group of 20-25 years old while the lowest percentage (16\%) was those $<20$ years. More than half $(56 \%)$ of the samples were from rural area. Concerning education level, $42 \%$ of mothers were illiterate, about husbands' education level, secondary school rated by $28 \%$ of respondents. In regard to occupation, most of the participants (90\%) were housewife.

\begin{tabular}{|c|c|c|}
\hline $\begin{array}{l}\text { Sociodemographic } \\
\text { characteristics }\end{array}$ & Frequency (F) & Percentage \\
\hline \multicolumn{3}{|l|}{ Age (years) } \\
\hline$<20$ & 24 & 16 \\
\hline $20-25$ & 51 & 34 \\
\hline $26-30$ & 39 & 26 \\
\hline$>30$ & 36 & 24 \\
\hline \multicolumn{3}{|l|}{ Residency } \\
\hline Rural & 84 & 56 \\
\hline Urban & 66 & 44 \\
\hline \multicolumn{3}{|l|}{ Education level } \\
\hline Illiterate & 63 & 42 \\
\hline Primary & 39 & 26 \\
\hline Secondary & 42 & 28 \\
\hline University/Institute & 6 & 4 \\
\hline \multicolumn{3}{|l|}{ Husband education level } \\
\hline Illiterate & 30 & 20 \\
\hline Primary & 30 & 20 \\
\hline Secondary & 42 & 28 \\
\hline University/Institute & 21 & 14 \\
\hline Postgraduate & 27 & 18 \\
\hline \multicolumn{3}{|l|}{ Occupation } \\
\hline Private sector worker & 9 & 6 \\
\hline Retired & 6 & 4 \\
\hline Housewife & 135 & 90 \\
\hline
\end{tabular}




\section{Pregnant Women Reproductive Variables}

Regarding obstetric history, the data presented in Table 2 show that of 150 pregnant women who participated in the study $(44 \%)$ indicated $(2-4)$ the previous pregnancy followed by $32 \%$ which were primigravida. In addition, $66 \%$ of the study sample indicated that they had not history of the previous abortion. Most of the mothers (70\%) were in the $3^{\text {rd }}$ trimester of her pregnancy followed by the $1^{\text {st }}$ and $2^{\text {nd }}(16 \%$ and $14 \%$, respectively). Findings of the present study revealed that more than half of mothers $(58 \%)$ had planned for their pregnancy.

\section{Knowledge of Pregnant Women about Minor Discomforts}

The evidence from this study showed that more than half (54\%) of the respondents previously heard about discomforts and $46 \%$ indicated that any pregnant woman can develop discomforts. Majority of participants $(68 \%)$ believed that it is important for pregnant women to know about discomforts during pregnancy. Our results revealed that $70 \%$ of women experienced discomforts during their pregnancy and the most frequent discomforts indicated by them were insomnia $(88 \%)$, nausea and vomiting $(82 \%)$, and backache $(78 \%)$, while few respondents $(18 \%)$ pointed hemorrhoid and constipation. These findings are shown in Table 3.

Friends $(32 \%)$ followed by media $(28 \%)$ were the most common source of information for pregnant women regarding the minor discomforts during pregnancy [Table 4].

As it was shown in Table 5, the knowledge of pregnant women classified into two levels and this study found that more than half of the study sample $(56 \%)$ had poor knowledge of minor discomforts during pregnancy while $44 \%$ of them showed good knowledge level.

\section{Association between Knowledge Level and Selected Variables}

Table 6 represented association of knowledge level of the study sample regarding minor discomforts during pregnancy with pregnant women sociodemographic variables. From cross-tabulation analysis (Chi-square value), it revealed statistically significant association between knowledge levels with pregnant education level $(P<0.05)$, and high significant association with other sociodemographic characteristics of age, husbands education level, and occupation $(P \leq 0.001)$.

In addition, from our findings, it can be noticed that there was statistically significant association between pregnant women knowledge and their reproductive variables of gravida $(P<0.05)$, abortion $(P<0.05)$, and type of pregnancy $(P \leq 0.001)$. These findings are shown in Table 7 .
Table 2: Reproductive characteristics of the study participants

\begin{tabular}{lcc}
\hline $\begin{array}{l}\text { Sociodemographic } \\
\text { characteristics }\end{array}$ & Frequency (F) & Percentage \\
\hline Gravida & 48 & 32 \\
1 & 66 & 44 \\
$2-4$ & 36 & 24 \\
$\geq 5$ & & \\
Abortion & 99 & 66 \\
None & 45 & 30 \\
$1-2$ & 6 & 4 \\
$>2$ & & \\
Gestational age & 24 & 16 \\
$1^{\text {st }}$ trimester & 21 & 14 \\
$2^{\text {nd }}$ trimester & 105 & 70 \\
$3^{\text {rd }}$ trimester & & \\
Type of pregnancy & 87 & 58 \\
Planned & 63 & 42 \\
Unplanned & & \\
\hline
\end{tabular}

Table 3: Pregnant women knowledge of minor discomforts

\begin{tabular}{|c|c|c|c|c|}
\hline \multirow[t]{2}{*}{ Variables } & \multicolumn{2}{|c|}{ Yes } & \multicolumn{2}{|c|}{ No } \\
\hline & $\mathbf{F}$ & $\%$ & $\mathbf{F}$ & $\%$ \\
\hline $\begin{array}{l}\text { Have ever heard of discomforts during } \\
\text { pregnancy? }\end{array}$ & 81 & 54 & 69 & 46 \\
\hline $\begin{array}{l}\text { Can any woman develop discomforts } \\
\text { during pregnancy? }\end{array}$ & 69 & 46 & 81 & 54 \\
\hline $\begin{array}{l}\text { Is it important to know discomfort } \\
\text { management at pregnancy? }\end{array}$ & 102 & 68 & 48 & 32 \\
\hline $\begin{array}{l}\text { Have you experienced any discomfort } \\
\text { at pregnancy? }\end{array}$ & 105 & 70 & 45 & 30 \\
\hline \multicolumn{5}{|c|}{ Name minor discomforts during pregnancy that you know? } \\
\hline Nausea and vomiting & 123 & 82 & 27 & 18 \\
\hline Heartburn & 96 & 64 & 54 & 36 \\
\hline Varicose vein & 39 & 26 & 111 & 74 \\
\hline Backache & 117 & 78 & 33 & 22 \\
\hline Frequency urination & 36 & 24 & 114 & 76 \\
\hline Leg cramps & 39 & 26 & 111 & 74 \\
\hline Fatigue & 114 & 76 & 36 & 24 \\
\hline Constipation & 27 & 18 & 123 & 82 \\
\hline Hemorrhoids & 27 & 18 & 123 & 82 \\
\hline Insomnia & 132 & 88 & 18 & 12 \\
\hline
\end{tabular}

Table 4: Pregnant women sources of knowledge (information)

\begin{tabular}{lll}
\hline Source of knowledge (information) & F & $\%$ \\
\hline Health-care personnel & 15 & 10 \\
Media & 42 & 28 \\
Family members & 24 & 16 \\
Friends & 48 & 32 \\
Other & 21 & 14 \\
\hline
\end{tabular}

Table 5: Pregnant knowledge level about minor discomforts

\begin{tabular}{lccc}
\hline Knowledge level & Score category & F & $\%$ \\
\hline $\begin{array}{l}\text { Poor knowledge } \\
(<50 \% \text { correct answer) }\end{array}$ & $\leq 7$ & 84 & 56 \\
$\begin{array}{l}\text { Good knowledge } \\
\text { (more than } 50 \%\end{array}$ & $\geq 8$ & 66 & 44 \\
correct answer) & & & \\
\hline
\end{tabular}


Table 6: Knowledge of minor discomforts in association with sociodemographic variables

\begin{tabular}{|c|c|c|c|c|c|}
\hline \multirow[t]{3}{*}{ Variable } & \multicolumn{4}{|c|}{ Knowledge level } & \multirow[t]{3}{*}{$P$-value } \\
\hline & \multicolumn{2}{|c|}{$\begin{array}{c}\text { Poor } \\
\text { knowledge }\end{array}$} & \multicolumn{2}{|c|}{$\begin{array}{c}\text { Good } \\
\text { knowledge }\end{array}$} & \\
\hline & $\mathbf{F}$ & $\%$ & $\mathbf{F}$ & $\%$ & \\
\hline \multicolumn{6}{|l|}{ Age (years) } \\
\hline$<20$ & 24 & 28.6 & 0 & 0 & ${ }^{*} P \leq 0.001$ \\
\hline $20-25$ & 24 & 28.6 & 27 & 40.9 & \\
\hline $26-30$ & 30 & 35.7 & 9 & 13.6 & \\
\hline$>30$ & 6 & 7.1 & 30 & 45.5 & \\
\hline \multicolumn{6}{|l|}{ Education level } \\
\hline Illiterate & 33 & 39.3 & 30 & 45.5 & 0.013 \\
\hline Primary & 27 & 32.1 & 12 & 18.2 & \\
\hline Secondary & 24 & 28.6 & 18 & 27.3 & \\
\hline University/Institute & 0 & 0 & 6 & 9.1 & \\
\hline \multicolumn{6}{|l|}{ Husband education level } \\
\hline Illiterate & 24 & 28.6 & 6 & 9.1 & ${ }^{*} P \leq 0.001$ \\
\hline Primary & 18 & 21.4 & 12 & 18.2 & \\
\hline Secondary & 36 & 42.9 & 6 & 9.1 & \\
\hline University/Institute & 6 & 7.1 & 15 & 22.7 & \\
\hline Postgraduate & 0 & 0 & 27 & 40.9 & \\
\hline \multicolumn{6}{|l|}{ Occupation } \\
\hline Private sector worker & 0 & 0 & 9 & 13.6 & ${ }^{*} P \leq 0.001$ \\
\hline Retired & 0 & 0 & 6 & 9.1 & \\
\hline Housewife & 84 & 100 & 51 & 77.3 & \\
\hline
\end{tabular}

${ }^{*}$ Fisher's exact test

Table 7: Knowledge of minor discomforts in association with reproductive variables

\begin{tabular}{|c|c|c|c|c|c|}
\hline \multirow[t]{3}{*}{ Variable } & \multicolumn{4}{|c|}{ Knowledge level } & \multirow[t]{3}{*}{$P$-value } \\
\hline & \multicolumn{2}{|c|}{$\begin{array}{c}\text { Poor } \\
\text { knowledge }\end{array}$} & \multicolumn{2}{|c|}{$\begin{array}{c}\text { Good } \\
\text { knowledge }\end{array}$} & \\
\hline & $F$ & $\%$ & $F$ & $\%$ & \\
\hline \multicolumn{6}{|l|}{ Gravida } \\
\hline 1 & 30 & 35.7 & 18 & 27.2 & \multirow[t]{3}{*}{0.007} \\
\hline $2-4$ & 42 & 50 & 24 & 36.4 & \\
\hline$\geq 5$ & 12 & 14.3 & 24 & 36.4 & \\
\hline \multicolumn{6}{|l|}{ Abortion } \\
\hline None & 60 & 71.4 & 39 & 59.1 & \multirow[t]{3}{*}{${ }^{*} 0.013$} \\
\hline $1-2$ & 24 & 28.6 & 21 & 31.8 & \\
\hline$>2$ & 0 & 0 & 6 & 9.1 & \\
\hline \multicolumn{6}{|l|}{ Gestational age } \\
\hline 1st trimester & 15 & 17.9 & 9 & 13.6 & \multirow[t]{3}{*}{0.189} \\
\hline 2nd trimester & 15 & 17.9 & 6 & 9.1 & \\
\hline 3rd trimester & 54 & 64.2 & 51 & 77.3 & \\
\hline \multicolumn{6}{|c|}{ Type of pregnancy } \\
\hline Planned & 33 & 39.3 & 54 & 81.8 & \multirow[t]{2}{*}{${ }^{\star} P \leq 0.001$} \\
\hline Unplanned & 51 & 60.7 & 12 & 18.2 & \\
\hline
\end{tabular}

${ }^{*}$ Fisher's exact test

\section{DISCUSSION}

Based on findings of the previous studies about minor illness or discomforts during pregnancy, it is demonstrated that despite being non-life threatening, the high prevalence of these conditions among pregnant women has a major effect on productivity and may have great impact on the mortality and morbidity in pregnant women. The main aim of the study was to evaluate existing knowledge regarding minor discomforts during antenatal period among pregnant women who attended maternal and pediatric hospital of Soran city.

In this study, the minor discomforts knowledge among participants was poor and more than half of respondents indicated poor knowledge. These findings supported by those of a study done in India by Dhanawade (2017). Findings of the present study also supported by another study done by Sarada et al., 2015, which assessed the knowledge regarding home management of minor ailments in pregnancy among urban women in India. Our findings are in contrast of the study conducted by Gururani et al. (2016) that the majority of antenatal mothers showed a good knowledge level.

In terms of minor discomforts, our findings demonstrated that out of all minor discomforts, insomnia and nausea and vomiting were the most frequent items which indicated by pregnant. Similar findings founded in a study of Kaur and Gagandeep (2017) in India which revealed that nausea/ vomiting is commonly prevalent in maximum number of antenatal mothers.

From the results of the present study, statistically significant associations were found between knowledge levels with pregnant women's age, education level, and occupation. Similar findings were also reported by Vincent et al., 2015; Aldossary et al., 2018; and Aziz and Maqsood, 2016.

In contrast of our results, recent studies done by Kaur and Gagandeep, 2017; Patil and Salunkhe, 2015; and Gamel et al., 2017, revealed no significant associations between knowledge levels with sociodemographic variables.

Significant association can be noticed from our results between pregnant women knowledge and their reproductive variables of gravida, abortion, and type of pregnancy. These findings are quite different from the study of Kaur and Gagandeep (2017) which revealed no relationship between mothers' knowledge and reproductive variables of gravida, gestational age. However, Aziz and Maqsood (2016) in a study revealed significant association between pregnant knowledge and gestational age.

\section{CONCLUSION}

Based on the findings, it can be concluded that knowledge of minor discomforts during pregnancy was unsatisfactory and there was statistically significant association between pregnant women knowledge level and selected 
sociodemographic characteristics of (age, education level, and occupation) and reproductive variables of gravida, abortion, and type of pregnancy. Further, research recommended on the topic as well as designing health education programs to help women understand their physiological changes and minor discomforts during pregnancy.

\section{REFERENCES}

Aldossary, A. D., S. A. Al Shamandy and A. A. Haitham. 2018. A cross sectional study about knowledge and practice of primigravida women: Minor and common pregnancy discomforts. J. Nurs. Health Sci. 4(1): 32-45.

Aziz, K. F. and S. H. Maqsood. 2016. Self management of pregnant women regarding minor discomforts in primary health care centers in Erbil city. Med. J. Babylon. 13(2): 284-293. Available from: http://www.medicaljb.com. [Last accessed on 2018 Feb 12].

Bala, M. 2017. A descriptive study to assess the prevalence of minor ailments during pregnancy, home care remedies adopted by primigravida mothers and to develop an information booklet regarding the management of minor ailments during pregnancy in a selected hospital of Delhi. Int. J. Nurs. Midwifery Res. 4(4): 3-13.

Dhanawade, A. R. 2017. A study to assess the effectiveness of planned teaching on knowledge regarding minor ailments during antenatal period among primigravida mothers in selected hospitals of Sangli city, Maharashtra, India. Int. J. Nurs. Res. 3(2): 79-82.

El-Khayat, I. A. 2007. Traditional management of gastrointestinal minor discomforts during pregnancy. Bull. High Inst. Public Health. 37(3): 737-757.

Fraser, D. M. and M. A. Copper., editors. 2004. Text Book for Midwives. $14^{\text {th }}$ ed. Churchill Livingstone Publishers, New York, p217-219.

Gamel, W. M. A., T. M. Fathy, A. M. R. El-Nemer and K. R. A. Shabana. 2017. Utilization of self-care brochure for relieving mother's minor discomforts during pregnancy. J. Nurs. Womens Health. 2: 108.
Gururani, L., A. Kumar and G. Mahalingam. 2016. Minor disorder of pregnancy and its home management. Int. J. Med. Sci. Public Health. 5(4): 684-687. Available from: http://www.ijmsph.com. [Last accessed on 2018 Apr 25].

Hanif, S. 2006. Frequency and pattern of urinary complaints among pregnant women. J. Coll. Phys. Surg. Pak. 16(8): 514-517.

Karnati, S. and V. Kumari. 2015. A study to assess the knowledge regarding home management of minor ailments in pregnancy among rural women. Int. J. Recent Sci. Res. 6(6): 4593-4596.

Kaur, A. and Kaur G. 2017. Assessment of the knowledge and expressed practices regarding self-management of minor ailments among antenatal mothers. IOSR J. Nurs. Health Sci., 6(1): 49-54. Available from: http://www.iosrjournals.org. [Last accessed on 2018 Feb 23].

Latha, P. and S. Indira. 2016. Effectiveness of IEC (information, education and communication) package on knowledge regarding minor ailments of pregnancy and its management among antenatal mothers at $\mathrm{NMCH}$, Nellore, A.P. Int. J. Appl. Res. 2(10): 593-596.

Patil, N. and J. Salunkhe. 2015. Assessment of knowledge on minor ailments of pregnancy and home remedies. Int. J. Sci. Res. 4(1): 674-677. Available from: http://www.ijsr.net. [Last accessed on 2018 Mar 05].

Pierce, H. 2010. Pregnancy-related Low Back and Pelvic Girdle Pain: Listening to Australian Women. Honors Thesis. University of Technology, Sydney, Australia.

Sangeetha, E., R. Shanghais and D. Revathy. 2015. A descriptive study to assess the level of knowledge on minor ailments in pregnancy among antenatal mothers in selected tertiary hospital, Kanchipuram, Tamilnadu. J. Nurs. Patient Saf. Care. 1(2): 1-6. Available from: http://www.tjprc.org. [Last accessed on 2018 Apr 16].

Sarada, K., K. B. Vanaja and A. Indra. 2015. Assess the knowledge regarding home management of minor ailments in Pregnancy among urban women. J. Med. Sci. Clin. Res. 3(6): 6341-6346.

Vincent, S. H., S. Nayak and S. H. Paul. 2015. A study on knowledge of primi mothers on self management of minor discomforts of pregnancy. Nitte Univ. J. Health Sci. 5(2): 12-15. 